JOAQUÍN VILLALBA ÁLVAREZ

(Universidad de Extremadura)

\title{
LA INDUSTRIA COMO CUALIDAD PROPIA DEL HISTORIADOR. Sobre la PERVIVENCIA de los Proemios de SAlustio EN LA HISTORIOGRAFÍA LATINA DEL RENACIMIENTO ${ }^{1}$
}

\section{Industria as a characteristic feature of the Historian. On the survival of Sallust's Prefaces in Renaissance Neo-Latin Historiography}

\begin{abstract}
In classical antiquity the debate arose about what was more important: human actions or their recreation in writing, in the form of history. Sallust perhaps stands out above the rest in this debate. The dichotomy between agere historiam and scribere historiam, which serves the historian to justify his work by placing it at the same level or even above the protagonist of events, became a recurring literary topic in later historiography, and particularly in Renaissance Neolatin historiography. Underlying this debate is the concept of industria, as an activity opposed to inaction, a concept assiduously repeated in the prefaces of Renaissance historiography, to reflect, in line with Sallust, the importance of the historian's work as a transmitter from past events to future generations, with all its practical and pedagogical implications. We analyze the presence of the word industria in the prefaces of some Neo-Latin historians, namely Poggio Bracciolini, Sánchez de Arévalo or Arnoul Le Ferron.
\end{abstract}

KEY WoRDS: Renaissance Neolatin Historiography; prefaces; industria; scribere historiam; Sallust; Poggio Bracciolini; Rodrigo Sánchez de Arévalo; Arnoul Le Ferron.

RESUMEN: Desde la Antigüedad clásica fue recurrente el debate de si eran más importantes las acciones humanas o su recreación por escrito, en forma de historia. Salustio destaca quizá por encima del resto en este debate. La dicotomía entre agere historiam y scribere historiam, que sirve al historiador para justificar y ponderar su labor situándola al mismo nivel o incluso por encima del protagonista de los hechos, se convirtió en un tópico literario repetido en la historiografía posterior, y de manera particular en las historias latinas del Renacimiento. Tras este debate se esconde el concepto de industria, en cuanto actividad frente a la inacción, un concepto que se repite con relativa asiduidad en los proemios historiográficos renacentistas, para reflejar, al hilo de Salustio, la importancia de la labor del historiador en cuanto transmisor de los hechos del pasado a las generaciones futuras, con todas las implicaciones prácticas y pedagógicas que ello conlleva. Analizamos la presencia del término industria en los prefacios de algunos historiadores neolatinos, como Poggio Bracciolini, Sánchez de Arévalo o Arnoul Le Ferron.

Palabras Clave: Historiografía latina del Renacimiento; proemios; industria; scribere historiam; Salustio; Poggio Bracciolini; Rodrigo Sánchez de Arévalo; Arnoul Le Ferron.

Fecha de Recepción: 29 de noviembre de 2020.

Fecha de Aceptación: 17 de diciembre de 2020.

${ }^{1}$ Este trabajo se enmarca en el Proyecto de Investigación FFI2015-64765-P del Ministerio de Economía del Reino de España y en el Grupo de Investigación LAPAR (HUM002) de la Junta de Extremadura. 


\section{Introducción. Origen y significado de industria}

$\mathrm{El}$ sustantivo industria es un abstracto del adjetivo arcaico indostruus (cuya forma evolucionada al latín clásico sería industrius), procedente con toda seguridad de la combinación de la partícula $e n d o^{2}$ (forma arcaica y reforzada del preverbio in) y la raíz indoeuropea *streu-, derivada a su vez de otra raíz *ster-, cuyo significado general es 'extender'. De la forma *streu- derivaría el verbo latino struo, con el significado de 'apilar', 'disponer horizontalmente en capas sucesivas', de donde la noción de 'construir'.

El significado que del vocablo industria aparece en los diccionarios es el de 'celo, actividad, dedicación o esmero', un significado que responde, según Festo, a la idea de actividad interior, realizada en secreto, "como si el que lleva a cabo alguna cosa la fuera construyendo interiormente y la trabajase en su casa". ${ }^{3}$ Autores como Bréal o Benveniste apoyan la hipótesis de que el significado original de industria tiene que ver con ese matiz de 'construcción desde dentro', y aducen como argumento la existencia de un verbo griego $\beta v \sigma \sigma o \delta o \mu \varepsilon v ́ \omega,{ }^{4}$ cuya presencia se constata ya en Hesíodo y Homero con el significado de 'construir en las profundidades', 'maquinar algo en secreto', con un sentido similar, aunque siempre teñido de un matiz claramente peyorativo. ${ }^{5}$

No obstante, cabe también la posibilidad de que el preverbio in- confiera a industria un valor de 'superposición', como se atestigua en el que sería su verbo correspondiente, instruere. Así, del mismo modo que imponere significa propiamente 'poner sobre', 'superponer', o infundere 'derramar sobre', instruere tendría el sentido, frente a struere, de 'construir por capas sucesivas', 'disponer una cosa encima de otra'. Con tal significado se usó originariamente en el lenguaje militar ('equipar', 'disponer', en el sentido de 'ir aprestando materiales para alguna acción’), de donde se obtendría el sustantivo instrumentum. Más adelante, ya en latín imperial, el verbo polarizaría su

2 Esta forma aparece evolucionada a indu- en autores arcaicos como Ennio, donde la encontramos varias veces como preverbio en la palabra induperator, y también como preposición (Enn. ap. Macr. S. 6.2 [Ann. 425 ed. Vahlen]: indu mari magno fluctus extollere certant). En latín clásico se mantuvo en algunos modificados, como indago, indigeo, indulgeo o industria.

${ }^{3}$ Fest. (ed. Müller), p. 106: Industrium antique dicebant indostruum, quasi qui, quicquid ageret, intro strueret et studeret domi.

${ }^{4}$ Cf. Bréal (1897: 145); Benveniste (1948: 117).

5 Aulo Gelio señala que industria formaba parte de cierto número de vocablos (gratia, valetudo, tempestas, facinus, etc.) que en latín arcaico podía tomarse en dos sentidos contrarios entre sí. Así, en el buen sentido ('dedicación', ‘esmero') o en el malo ('maquinación’). Cf. Gell. 12.9.1. 
significado en un sentido nocional, en cuanto 'aportar conocimientos', 'fortalecer o desarrollar intelectualmente', 'formar'.

Así pues, el sustantivo industria reflejaría el proceso constante de construir poco a poco alguna cosa, de donde derivaría el significado que encontramos en los diccionarios, como 'disposición o predisposición a hacer cosas', 'dedicación', 'esmero', 'perseverancia'. Y ello es algo que se puede comprobar fácilmente si echamos un vistazo a los sustantivos de significado afín con que suele aparecer a menudo coordinado en los textos, tales como studium, vigilantia, cura, vigor, virtus, labor o diligentia, entre otros.

\section{Presencia en lengua latina. El caso particular de Salustio}

Con respecto al uso del término en la literatura latina, hemos contabilizado algo menos de seiscientos casos que se extienden desde las primeras manifestaciones literarias de época arcaica hasta los albores del siglo III. ${ }^{7}$

Por géneros, llama la atención la presencia tanto del sustantivo industria como de sus derivados adjetivales (industrius) y adverbiales (industrie, industriose) en escritos de tipo retórico, fundamentalmente en Cicerón, el autor que de largo usa más el término y sus derivados (159 casos), pero también en Quintiliano (19), en la Retórica a Herenio (16) o en Séneca el Rétor (11). También es significativa la presencia del término en géneros como la filosofía (en particular Séneca) o la literatura técnica (Vitruvio o Columela, entre otros).

Pero si hay un género que puede estar al mismo nivel que la retórica en cuanto a la frecuencia de uso, ése es la historiografía. A este respecto, la nómina de historiadores que recurren al empleo de industria y sus derivados es bastante amplia, y se extiende a lo largo de todas las épocas de la literatura latina, desde los Origines de Catón, pasando por Julio César, Salustio, Nepote, Asinio Polión, Tito Livio, Valerio Máximo, Veleyo Patérculo, Curcio Rufo, Tácito o Suetonio hasta llegar a Floro y Justino. ${ }^{8}$

6 Cf. Valpy (1828), s. v. industria: "Instruo is to build up, and may mean to put together, establish, improve, in opposition to destruo, to destroy. Industria then will be that talent by which instruimus mentem doctrina aut instruimus i. e. amplificamus res. Esta misma idea de 'desarrollo' o 'crecimiento' se observa en términos como esp. alumno ( $<$ lat. alere) o fr. élève e ital. allievo ( $<$ lat. elevare). Por otra parte, precisamente esta transferencia de significados al ámbito nocional explicaría la creación de un verbo como superstruo, que vendría a sustituir el matiz espacial que instruo tendría en origen y que habría perdido a partir del latín imperial.

${ }^{7}$ A los casos del sustantivo industria (514) habría que añadir los casos del adjetivo industrius (41) y de los adverbios industrie e industriose (24), lo que hace un total de 579 casos en la literatura latina hasta el siglo III.

${ }^{8} \mathrm{Al}$ empleo por parte de estos historiadores cabría sumar el de otros autores que, de alguna manera, escriben sobre hechos del pasado, como Varrón, Plinio el Viejo o Aulo Gelio. 


\section{TALIA DIXIT 15 (2020), 57-75}

Concretamente en Valerio Máximo, y en un capítulo que precisamente lleva por título De studio et industria, encontramos un encendido elogio de la industria, a la que no duda en considerar como perfectissima virtus que se consolida con la práctica continuada, y que contribuye a alcanzar la gloria en cualquier actividad que se lleve a cabo mediante el espíritu, las manos o la lengua:

Quid cesso uires industriae commemorare, cuius alacri spiritu militiae stipendia roborantur, forensis gloria accenditur, fido sinu cuncta studia recepta nutriuntur, quidquid animo, quidquid manu, quidquid lingua admirabile est, ad cumulum laudis perducitur? Quae cum sit perfectissima uirtus, duramento sui confirmatur. (Val. Max. 8.7, init.).

No obstante, en esta ocasión quiero fijar mi atención en el empleo que del término hace un historiador como Salustio, donde el concepto se relaciona con la virtus de los romanos primitivos, en claro retroceso en su tiempo; de este modo, cuando aparece el término, va siempre asociado a algún personaje garante de esa primitiva moralidad romana. ${ }^{9}$ Ello explica su presencia en determinados pasajes de la obra salustiana, y en particular en tres componentes básicos de la misma, como son los discursos, los retratos y los proemios, instrumentos todos ellos de enorme eficacia para plasmar su concepción moralista de la historia, su visión positiva o negativa de los personajes que forman parte de ella.

En cuanto a los discursos, es significativa la presencia del término industria en la alocución que Catón el Joven, por entonces tribuno de la plebe, pronuncia ante el Senado en el Bellum Catilinarium; en dicha alocución afirma que lo que hizo grandes a los romanos del pasado no fue el poderío de sus armas, sino la pujanza de sus virtudes, entre ellas su perseverancia, esto es, su industria:

Sed alia fuere, quae illos magnos fecere, quae nobis nulla sunt: domi industria, foris iustum imperium, animus in consulundo liber, neque delicto neque lubidini obnoxius (Sall. Cat. 52.21)

Por lo que respecta a los retratos, destacan los que Salustio nos presenta de Mario y Sila en el Bellum Ingurthinum, en que se alternan buenas cualidades de ambos personajes junto con otras más negativas. De Sila se subraya su buena suerte, sólo comparable a su perseverancia:

${ }^{9}$ Salustio emplea el sustantivo industria en catorce ocasiones (incluidas aquellas que aparecen en las cartas espurias dirigidas a César), a las que cabe sumar un único caso del adjetivo correspondiente, industrius. 
Atque illi felicissimo omnium ante civilem victoriam numquam super industriam fortuna fuit (Sall. Ing. 95).

De Mario, por su parte, refiere Salustio que, a excepción de un origen noble, atesoraba el resto de cualidades necesarias para ser cónsul, entre ellas su perseverancia, su honradez, su gran conocimiento de la milicia o su dominio de las pasiones:

At illum iam antea consulatus ingens cupido exagitabat, ad quem capiendum praeter vetustatem familiae alia omnia abunde erant: industria, probitas, militiae magna scientia, animus belli ingens domi modicus, lubidinis et divitiarum victor, tantummodo gloriae avidus (Sall. Ing. 63).

Junto con los discursos y los retratos, también los proemios sirven a este propósito moralista. De ahí que no resulte extraño que el término industria aparezca también en estos pasajes programáticos, y de manera más pronunciada en el proemio del Bellum Ingurthinum, donde aparece hasta en cuatro ocasiones, y en un sentido que se incardina claramente en esta concepción moralista de la historia de la que venimos hablando y que vertebra toda la obra histórica de Salustio.

Mucho se ha escrito sobre las reflexiones que pueblan los capítulos iniciales de ambas monografías salustianas. ${ }^{10} \mathrm{El}$ ser humano está formado de cuerpo y alma: el primero lo tiene en común con los animales, la segunda la comparte con los dioses. El alma -dice Salustio- es la que guía y dirige realmente la vida de los mortales (dux atque imperator vitae mortalium animus est), ${ }^{11}$ es la que actúa, todo lo domina y no se deja dominar. ${ }^{12}$ Por eso sorprende que algunos se dejen llevar por los placeres del cuerpo o el capricho de la fortuna -bienes efímeros- en vez de emplear sus cualidades intelectuales (ingeni egregia facinora) ${ }^{13}$ en alguna actividad que le reporte fama y gloria imperecederas.

El comienzo del Bellum Iugurthinum es un ejemplo sintomático en este sentido: erróneamente, el hombre se lamenta de su naturaleza mortal y efímera, cuando en realidad lo que debería hacer es esforzarse y trabajar con denuedo y perseverancia para alcanzar la gloria y domeñar a la fortuna. Como decimos, el término industria

10 Sirvan de ejemplo trabajos clásicos como el de Rambaud (1946), Giancotti (1971) o Tiffou (1973), entre otros muchos.

11 Sall. Ing. 1.

12 Animus incorruptus, aeternus, rector humani generis agit atque habet cuncta neque ipse habetur (Sall. Iug. 2).

13 Cf. Earl (1959: 156): "For Sallust virtus consists precisely in winning gloria by the use of ingenium to commit egregia facinora". O también Earl (1961: 28), donde se define la virtus como "the functioning of ingenium to achieve egregia facinora, and thus to win gloria through bonae artes". 
aparece hasta en cuatro ocasiones en los preliminares de la obra, lo que es síntoma de la importancia y la significación que Salustio le concede en el contexto reflexivo y moralista en que se mueve en estos capítulos iniciales. El autor comienza reflexionando sobre las vanas quejas de los mortales, que ansían una vida más longeva o una mayor fuerza, cuando en realidad lo que falta a la naturaleza humana es una mayor perseverancia y dedicación constante en sus acciones:

Falso queritur de natura sua genus humanum, quod inbecilla atque aevi brevis forte potius quam virtute regatur. Nam contra reputando neque maius aliud neque praestabilius invenias magisque naturae industriam hominum quam vim aut tempus deesse. Sed dux atque imperator vitae mortalium animus est. Qui ubi ad gloriam virtutis via grassatur, abunde pollens potensque et clarus est neque fortuna eget, quippe quae probitatem, industriam aliasque artis bonas neque dare neque eripere cuiquam potest (Sall. Ing. 1).

La industria es, por tanto, uno de los conceptos que aparecen con cierta recurrencia en estas piezas programáticas de Salustio, como reflejo de los valores morales tradicionales que escasean en la Roma de su tiempo, más dada a rivalizar en riquezas que en virtudes: ${ }^{14}$

At contra quis est omnium his moribus, quin divitiis et sumptibus, non probitate neque industria cum maioribus suis contendat? (Sall. Iug. 4).

Como personaje retirado de la vida pública, Salustio ha decidido servir activamente a su patria por otra vía: por medio de la escritura de la historia, una actividad sumamente útil a la sociedad que además reporta fama y gloria a quien la ejerce. ${ }^{15}$ Esta pretensión del Salustio historiador, que recoge de manera diáfana la expresión pulchrum est bene facere rei publicae, etiam bene dicere haud absurdum est ${ }^{16}$ responde a la propia justificación personal de su labor ante el lector, pues desde el punto de vista de un romano, alcanzar la gloria protagonizando algún hecho digno de memoria estaba muy por encima de hacerlo mediante la literatura. De ahí que en sus proemios reivindique la importancia del historiador, como transmisor al futuro de los gloriosos hechos del pasado. Sale así al paso de quienes quieran tachar su nueva ocupación de

${ }^{14}$ Cf. Earl (1961: 12): “industria was for Sallust one of the qualities most lacking in the Rome of his day; it is one of the most important factors in the striving for gloria which is man's proper aim (e. g. B. J. 1.2 and 4) and its absence is closely allied with the rise of the vices connected with ambitio and avaritia (e. g. B. C. 53.5). Cicero's dictum 'ingenium industria alitur' (Pro Cael. 19.45) fits well Sallust's view of the matter".

15 Cf. Sall. Ing. 4: Ceterum ex aliis negotiis, quae ingenio exercentur, in primis magno usui est memoria rerum gestarum.

16 Cf. Sall. Cat. 3. 
ociosidad. La acción, pues, no se limita al desempeño de un cargo político o militar, sino también al ejercicio de alguna actividad intelectual y útil a la sociedad, como es el relato de los gloriosos hechos del pasado. Frente a la socordia o la ignavia que dominan a algunos hombres, Salustio reivindica la industria, la perseverancia, el tesón, el empeño en hacer cosas que redunden en provecho del bien común:

Atque ego credo fore qui, quia decrevi procul a re publica aetatem agere, tanto tamque utili labori meo nomen inertiae imponant, certe quibus maxima industria videtur salutare plebem et conviviis gratiam quaerere (Sall. Ing. 4).

Es significativo que, acto seguido, el autor llegue a afirmar que su ocio redundará en mayor beneficio a la patria que la actividad de otros: maiusque commodum ex otio meo quam ex aliorum negotiis rei publicae venturum. Sin duda, Salustio tiene en mente el famoso dicho de Catón que pertenece al prólogo de sus Origines y que conocemos gracias a Cicerón: los hombres eximios deben dar cuenta por igual de su otium y de su negotium, esto es, tanto o más importante es saber a qué dedican su tiempo libre los hombres ilustres, una vez han abandonado la vida pública, que en qué han estado ocupados; una clara defensa de la escritura de la historia y sus provechosos efectos para la sociedad. ${ }^{17}$

En definitiva, la aparición de un término como industria, así como otros de significado afín como pueden ser studium, cura o labor, sirve a Salustio para poner de relieve la importancia del esfuerzo y la dedicación constante en el desarrollo de las acciones humanas, como elemento fundamental para alcanzar la virtus. Desde su perspectiva personal como historiador, el uso que Salustio hace de industria tiene que ver con la justificación de su labor historiográfica, que el propio autor pretende reivindicar ante el lector, situándola al mismo nivel o incluso por encima del protagonista de la historia. De este modo, industria se erige en un término importante en la célebre dicotomía salustiana entre scribere historiam y agere historiam.

\section{El término industria en la bistoriografía posterior}

La industria como cualidad deseable para el historiador no sólo aparece en los preliminares de la obra de Salustio. Al final de la praefatio a su epítome de las Historiae Philippicae de Trogo, Justino también usa el término apelando a la perseverancia y dedicación que ha demostrado al componer su obra, que sin duda sabrán valorar los

17 Cic. Planc. 66: clarorum virorum atque magnorum non minus otii quam negotii rationem extare oportere (Cic. pro Planc. 66). Cf. Miller (2015: 247). 
lectores futuros, cuando ya se haya desvanecido cualquier maledicencia o envidia de parte de sus coetáneos. ${ }^{18}$

La influencia de Salustio en la historiografía posterior está fuera de toda duda, y ha sido estudiada en profundidad por la filología moderna. De un modo general, su concepción típicamente moralista de la historia, su trasfondo pesimista, su lengua o su estilo están presentes en historiadores latinos del Imperio como Tácito o Amiano Marcelino. Su importancia perduró a lo largo de la literatura medieval, en los Padres de la Iglesia o en Juan de Salisbury, por poner sólo unos ejemplos; e incluso fue de los pocos historiadores clásicos que se siguió enseñando en las escuelas medievales, por lo que su vigencia en este período está fuera de toda duda. ${ }^{19}$

Pero quizá donde su huella se percibe de un modo más claro es entre los historiadores renacentistas: el pensamiento de Salustio se adivina ya en las primeras historias escritas a comienzos del Quattrocento italiano, entre ellas en especial en la historia florentina de Bruni. ${ }^{20}$ Por esta época comienzan a aparecer también por toda Europa las primeras ediciones y traducciones del autor en lengua vernácula, como la versión castellana de Francisco Vidal de Noya, o la italiana de Ludovico Carbone, ambas del último tercio del siglo XV.

Pues bien. Uno de los aspectos en los que se aprecia claramente la influencia de Salustio en los humanistas latinos del Renacimiento es en los proemios; en estas piezas introductorias es habitual encontrarse alguna referencia a la concepción salustiana de la historia, a veces de manera explícita, a veces entre líneas. Dicho de otro modo, las reflexiones que encontramos en los proemios de Salustio tuvieron una importancia capital en la manera de presentar la historia en siglos posteriores y llegaron a convertirse en lugar común en la historiografía latina del Renacimiento.

En las páginas que siguen es nuestro propósito analizar la presencia asidua que el concepto de industria siguió teniendo en los proemios historiográficos de tipo reflexivo e intención moralista que se escribieron a lo largo del período renacentista, un período que destaca justamente por el auge de un género como el historiográfico, en cuanto vehículo de legitimación y difusión de nuevas realidades

18 Iust., praef: Sufficit enim mihi in tempore iudicium tuum: apud posteros, cum obtrectationis inuidia decesserit, industriae testimonium habituro.

${ }^{19}$ Cf. Smalley (1971: 168): "Sallust alone of ancient historians survived that reduction of school texts which marked the decline of culture in the late empire in the West. He owed his survival, I suppose, to his brevity, to his pithiness, to his moralism".

20 Cf. Fryde (1983: 6): “Bruni's conception of how history might be written was also much influenced by Sallust, a writer known to many medieval historians. Bruni's ideological assumptions were notably clarified and sharpened by the reading of Bellum Iugurthinum and Bellum Catilinae". O también La Penna (1968: 409-431), quien dedica un capítulo de su Sallustio e la 'rivolurione' romana precisamente al peso de Salustio en la historiografía y en el pensamiento político de Bruni. 


\section{TALIA DIXIT 15 (2020), 57-75}

nacionales y de determinados regímenes políticos. En concreto, vamos a fijar nuestra atención en tres piezas preliminares pertenecientes a otras tantas obras historiográficas escritas entre los siglos XV y XVI por humanistas oriundos de diferentes territorios de Europa, y que tienen en común la referencia explícita al concepto de industria, en un tono que recuerda de manera marcada y nada casual a los proemios de Salustio. Nos referimos a las Historiae de varietate fortunae, obra escrita a mediados del siglo XV por el gran humanista toscano Gianfrancesco Poggio Bracciolini; la Compendiosa historia Hispanica del español Rodrigo Sánchez de Arévalo, aparecida en 1470; y los De rebus gestis Gallorum libri IX del francés Arnoul Le Ferron, publicada en 1550 .

\subsection{Las Historiae de varietate fortunae de Poggio Bracciolini.}

Contemporáneo de otros humanistas italianos metidos a historiadores como Lorenzo Valla y Leonardo Bruni, el toscano Poggio Bracciolini (1380-1459) es conocido en su faceta como historiador principalmente por los Historiarum Florentini populi libri VIII, una historia de Florencia que compuso al final de su vida y que abarcaba desde mediados del siglo XIV hasta su propio tiempo. Pero antes de ésta había escrito una obra cuando menos peculiar, a medio camino entre un tratado moral y una historia: las Historiae de varietate fortunae. Se trata de un escrito que pretende reflejar el protagonismo de la fortuna en las cosas humanas a lo largo de los tiempos. Se centra, pues, en el tema de la fortuna y cómo se manifiesta en los hombres y en los estados. ¿Y qué mejor manera de ilustrar ese papel trascendental de la fortuna en la vida de los hombres que recurriendo a los ejemplos del pasado?

Dividida en cuatro libros de diferente tenor y estilo, y compuesta en tiempos del papa Eugenio IV (entre 1431 y 1448), esta obra fue finalmente dedicada a su sucesor, ese gran protector de las humanidades que fue el papa Nicolás V. Bracciolini comienza su prefacio con la recurrente alabanza de la historia: hechos ilustres -nos dice el autor- los ha habido en todas las épocas, incluso en tiempos del legendario rey asirio Nino, pero la falta de historiadores sumió tales hechos en el más profundo de los abismos del olvido. La historia, por tanto, es beneficiosa para el ser humano, por las útiles enseñanzas que atesora y que debemos seguir o evitar, según el caso. Sólo ella es defensora tenaz y recuerdo fiel del pasado, sólo ella pone ante nuestros ojos, como si acabaran de suceder, las acciones que el paso del tiempo suele borrar. Nadie, en definitiva, conocería las gestas de los más afamados varones sin esa luz que aporta la historia. La oposición entre la luz del conocimiento y la oscuridad del olvido se hace evidente en el siguiente pasaje:

Magnam igitur utilitatem afferre mortalibus historia censeri debet et plurimi extimandam, beneficio cuius tum dicta, tum facta superiorum, haud quaquam 


\section{TALIA DIXIT 15 (2020), 57-75}

oblivione hominum sepulta, ad hec usque tempora magna ex parte propagata sunt. Hec diligens custos et fida preteritorum memoria dicenda est; hec sola illustrium virorum facta virtutesque nostro in conspectu ad imitandum proponit; hec detestatur vitia et docet vitanda; huius ope preterita representantur nobis et que vetustas solet delere, reddit tanquam recentia. Nullus quippe priscas et ab etate nostra remotas excellentium virorum gestas res nosset, nisi litterarum monumentis et historie munere in luce hominum versarentur (Bracciolini, Historiae de varietate fortunae, ed. Merisalo, p. 89).

El proemio incluye a continuación el viejo tópico -visible entre otros en Salustio- de que la grandeza de Roma se debe, tanto o más que a sus valerosos héroes, a los escritores que la encumbraron eternamente en sus obras. Sostiene Bracciolini que igual que conocemos la historia de Grecia y Roma gracias a los escritos de Homero, Heródoto, Virgilio o Livio, así también los grandes varones de su tiempo sólo perdurarán si cuentan con escritores que perpetúen sus acciones. Y ello sólo se consigue merced a la figura del historiador, cuyos esfuerzos van encaminados a salvar del olvido los hechos del pasado. Es en este punto donde vuelve a aparecer el término industria:

Accessit enim ad earum memoriam scribentium labor et industria que illa ab interitu vendicarent (Bracciolini, Historiae de varietate fortunae, ed. Merisalo, p. 89).

De ahí pasa a centrarse en el tema de la fortuna, y en cómo el ser humano prefiere dejarse llevar por lo efímero y casual, en lugar de perseguir la gloria a través de la virtud y la sabiduría, bienes mucho más sólidos que los que brinda la fortuna. También aquí están presentes, a nuestro juicio, las reflexiones que Salustio incorpora a sus proemios, en torno a la célebre dicotomía entre cuerpo y alma, entre los bienes efímeros y sujetos a la fortuna que aquél nos proporciona y los beneficios imperecederos que emanan de ésta. Bracciolini dibuja al ser humano como un actor que representa un papel en lo que él mismo denomina "el teatro de la fortuna", de modo que, cuando ésta deja de favorecerle, lo baja de su pedestal convirtiéndolo en un mimo ridículo y haciéndole ver su insensatez. De manera análoga a como hace Salustio, el humanista toscano viene a decir que los ejemplos de la historia nos enseñan el camino de la virtud, eligiendo entre los bienes imperecederos del alma y los placeres fugaces del cuerpo.

\subsection{La Compendiosa Historia Hispánica de Rodrigo Sánchez de Arévalo}

El pedagogo, diplomático e historiador español Rodrigo Sánchez de Arévalo (1404-1470) pasó la mayor parte de su vida en Roma. Allí entró en contacto con los más brillantes intelectuales de la época, entre ellos el humanista Eneas Silvio 
Piccolomini, que luego se convertiría en el papa Pío II. Ya al final de sus días pudo terminar su obra histórica más ambiciosa, a la que tituló Historiae Hispanicae partes quatuor, si bien es más conocida como Compendiosa historia hispánica. Se publicó en Roma el año de su muerte, 1470. Se trata, en contra de lo que pudiera parecer por el título, de una historia de Castilla, con la que el autor pretende justificar la grandeza de los hechos de su patria defendiéndose frente a los reiterados e infundados ataques vertidos desde fuera, y de manera especial desde Italia.

Ese tono apologista se ve ya en el proemio que sirve de presentación a la obra y que va dedicado al rey Enrique IV de Castilla. En él, Arévalo comienza exaltando la grandeza de los hechos de España, que no desmerecen en absoluto de los acometidos por griegos y romanos. Esta reflexión le lleva irremediablemente a evocar la célebre "comparación salustiana de los romanos activos con los griegos contemplativos", ${ }^{21}$ consistente en atribuir la fama y fortuna de los griegos al esfuerzo y dedicación de sus historiadores - de nuevo nos encontramos con el término industria-, en tanto que los romanos prefirieron ejercitar su talento en las armas y no en las letras. ${ }^{22}$ Adaptando el pensamiento de Salustio a la realidad castellana, Arévalo lamenta que esa fortuna de los griegos -que él hace extensiva también a persas y romanos- nunca ha alcanzado a los españoles, que siempre han preferido actuar (facere) antes que hablar (dicere), lo que ha devenido en una inopia scriptorum análoga a la que Salustio advertía entre sus compatriotas:

Idque ut arbitror ob scriptorum inopiam contigisse putandum est, quemadmodum de gestis Romanorum Salustius in Cathelinario conqueritur. Invidet enim Atheniensibus quod res suas scribentium industria longe illustriores in toto orbe quam fuerint referantur. Nec aliter de rebus Hispanicis dici potest, nam et Persarum, Graecorum et Romanorum gesta licet amplissima fuerint, verum aliquanto forsan inferiora quam fama ferantur. Sed quia magna scriptorum ingenia ea lustrarunt per orbem terrarum pro maximis celebrata sunt. Hispanica tamen gens nunquam habuit talem copiam scriptorum, quia pauci ingenium sine corpore exercebant, et quilibet optimus vir potius volebat facere quam dicere. Cupiebatque amplius sua bene facta laudari quam ipse aliorum bene facta narrare (R. Sánchez de Arévalo, Compendiosa bistoria Hispanica, prologus).

21 Son palabras de Tate (1970: 109). Esta evocación de Salustio es una constante en la literatura hispana que aún perduraba en época de Quevedo, como recuerda el propio Tate un poco más abajo, cuando cita un pasaje de La hora de todos en el que se refleja esa ausencia de historiadores hispanos: "Servíase su valentía de ajenas plumas; tomaron para sí el obrar, dejaron a los latinos el decir; en tanto que no supieron ser historiadores, supieron merecerlos".

22 Sall. Cat. 8: Sed quia provenere ibi scriptorum magna ingenia, per terrarum orbem Atheniensium facta pro maxumis celebrantur. [...] At populo Romano numquam ea copia fuit, quia prudentissumus quisque maxume negotiosus erat: ingenium nemo sine corpore exercebat, optumus quisque facere quam dicere, sua ab aliis benefacta laudari quam ipse aliorum narrare malebat. 
Es, pues, la industria de los historiadores griegos la que ha inmortalizado las hazañas de su pueblo, y no las hazañas en sí mismas. Tras esta reivindicación de la historia y de su utilidad, en la línea de Salustio, la intención última que persigue Arévalo es establecer una doble correspondencia entre los afortunados griegos y los italianos de su tiempo por una parte, y entre la Roma carente de escritores retratada por el autor clásico y los castellanos de su tiempo, por otra. En el fondo, lo que subyace es una crítica a ciertos humanistas italianos que seguían pensando que Italia era el centro del mundo y España no era más que una región situada en un extremo confín. Como señala Tate, está claro que Arévalo tiene en mente a Bruni aunque no lo nombre, pues reproduce fielmente las palabras del aretino en una de sus cartas, cuando decía despectivamente que los españoles vivían in extremo mundi angulo. ${ }^{23} \mathrm{En}$ efecto, como podemos seguir leyendo un poco más abajo en el prólogo de Arévalo, hay quienes se niegan a conocer la historia de España por estar situada en un rincón remoto del mundo, cuando en realidad ya los cosmógrafos de la Antigüedad comenzaron sus descripciones geográficas a partir de la Península Ibérica, como si ésta fuera la puerta de entrada al orbe. ${ }^{24}$

Un castellano militante como Rodrigo Sánchez de Arévalo, que llevaba ya bastantes años afincado en Roma, estaba sin duda al tanto del arrogante desconocimiento hacia todo lo hispano que se percibía entre los intelectuales italianos, que se las daban de herederos legítimos -y únicos- de la grandeza de Roma. De hecho, dicho menosprecio constituye seguramente el germen que llevó al segoviano a escribir su Compendiosa Historia Hispanica, que serviría por igual para rebatir cualquier calumnia proveniente de fuera y para paliar el escaso conocimiento que de España se tenía entre las élites intelectuales europeas. De ahí que el autor escribiera en latín, para público conocimiento de los hombres de letras de cualquier rincón de Europa. Arévalo venía de este modo a continuar la senda marcada por su maestro, el burgalés Alfonso de Cartagena, quien años antes había escrito, también en latín, una Anacephaleosis movido por idénticas razones. ${ }^{25}$

23 Cf. Bruni, Epistolarum libri octo, pars secunda (ed. L. Mehus 1741), p. 83-84: Illud etiam leve, quod Italicos statim calamum arripere inquit, quod otiosi sint: Hispanos vero, quod regia curia sint occupati, calamo vacare non posse. Quasi vero Itali non curiam habeant Romanam multo certe maiorem, quam sit regia, et infinitas publicarum privatarumque rerum occupationes. Nec sane consentaneum est, ut in extremo mundi angulo plus humanarum occupationum fit, quam in medio. Cf. Tate (1970: 81) y también Alvar Nuño (2018: 30-32).

24 Caeterum nonnulli Hispanas res legere dedignantur, eo ut puto errore ducti, quo nonnulli bonarum artium ac rerum inexperti; quod in angulo mundi, ut aiunt, Hispania sita esse videatur; contendunt atque extra orbem posita. Ut eorum verbis utar, ab orbis gloria aliena videatur: longe aliter sapientes cosmographi sensere, qui orbem descripturi; ab Hispania tanquam a principali orbis porta incepere (Sánchez de Arévalo, Compendiosa historia Hispanica, prologus).

25 Ambos habían podido comprobar de primera mano ese ambiente desdeñoso y altivo hacia los españoles tanto en el Concilio de Basilea como más adelante, en su prolongada estancia en Roma. 


\subsection{El De rebus gestis Gallorum de Arnoul Le Ferron}

Terminamos este recorrido por la historiografía renacentista con uno de los ejemplos quizá más claros de la impronta de Salustio en los proemios historiográficos de los siglos XV y XVI, el que nos brinda el historiador francés Arnoul le Ferron (1515-1563). Magistrado, miembro del parlamento de Burdeos y gran amigo del humanista Julio César Escalígero, retomó la redacción del De rebus gestis Francorum que el humanista italiano Paolo Emili dejó inconcluso cuando le sobrevino la muerte en $1529 .{ }^{26}$ En 1550 aparecieron publicados en París los De rebus gestis Gallorum libri IX ad historiam Pauli Aemilii additi, que como reza el título contiene nueve libros más de la historia de Francia, añadidos a los de Emili, que abarcan desde los tiempos de Carlos VIII hasta la muerte de Francisco I y el advenimiento de Enrique II, en 1547.

En el prefacio que sirve de presentación a la segunda edición de la obra, de 1554, ${ }^{27}$ Le Ferron introduce -como también hiciera Emili- ${ }^{28}$ numerosos elementos que recuerdan inevitablemente a Salustio y que giran de manera especial sobre el concepto típicamente salustiano del pesimismo ante la corrupción del tiempo presente. El texto comienza con una reflexión en torno a las tres razones que, para Le Ferron, llevaron a los hombres de la Antigüedad a escribir historia:

1) Laudis studium, el afán de gloria personal del historiador.

2) Illustrandae patriae studium, el afán por enaltecer los hechos de una nación.

3) Veritatis proponendae studium, el deseo de decir la verdad para que sirva de ejemplo a las generaciones futuras.

${ }^{26}$ El éxito de esta obra inconclusa de Emili queda de manifiesto por su pronta traducción al francés, a cargo de Jean Regnart, en 1581, así como por el interés que despertó entre varios historiadores en lengua latina, que emprendieron la tarea de continuarla. Primero Daniele Zavarizzi, otro humanista italiano que completó el libro X que Emili no tuvo tiempo de terminar y publicó toda la obra en París en 1539. Más adelante, Le Ferron continuó la historia hasta los tiempos de Enrique II (1547). A principios del siglo XVII, Jacob Henricpetri prosiguió la narración hasta 1600.

27 Nos decantamos por el proemio de la segunda edición de 1554 porque contiene algunos pasajes añadidos por el propio Le Ferron que no aparecían en la edición original de 1550 y que consideramos de gran valor para nuestro análisis.

${ }^{28}$ El proemio que Paolo Emili compone a su De rebus gestis Francorum está lleno de referencias claramente salustianas. Amén de alusiones explícitas a conceptos tales como la virtus, la fortuna o la libido, incide al principio del prefacio en ese hermosísimo debate interrumpido durante siglos sobre qué es más beneficioso para el hombre: que los grandes hombres lleven a cabo acciones honrosas, o que escritores de reconocido prestigio perpetúen dichas acciones a través del relato histórico: Pulcherrimum enim certamen per multa secula intermissum tandem repeteretur, ac utrum illustre opibus proceres sua aetate praeclara facinora edendo an nobiles fide scriptores in omne tempus profutura memoriae prodendo, plus utilitatis mortalibus afferant ambigeretur. 
Partim enim laudis studio ducti, cum esse hanc unam quae tantos labores posteritatis memoria consolaretur intelligerent, partim studio illustrandae patriae praemiisque a populis Regibusve propositis, partim studio veritatis proponendae similibusque aliis causis, exempla ut proponerent posteris unde quod imitarentur acciperent, id aggressi sunt (Le Ferron, De rebus gestis Gallorum, praef.).

Gloria personal, propaganda nacionalista y ejemplaridad son, pues, los tres ejes sobre los que los antiguos construyeron sus historias, según nos dice el religioso bordelés. En los tres casos, ese studium que movió a los hombres del pasado a escribir historia se ha convertido para Le Ferron en un riesgo y una dificultad en su propio tiempo:

1. Buscar la gloria y el reconocimiento personal no tiene sentido para el autor en una época en que se menosprecia el esfuerzo ajeno y se ensalza exclusivamente el propio:

Ac mihi quidem laudem sperare hoc seculo, cuius ea hactenus labes et macula fuit aliorum labores aut ridere aut contemnere, suos sine rivali laudare, sani hominis non videbatur (Le Ferron, De rebus gestis Francorum, praef.).

2. La alabanza de la nación es a priori un elemento que atenta contra la primera ley de la historia, que es decir la verdad. Y es en este punto donde Le Ferron hace alusión a la industria, como actitud vital tanto en la vida pública como en la literatura y que en su tiempo ha sido suplantada por bienes efímeros como las riquezas, hasta el punto de que las personas cultas y laboriosas no reciben premio alguno a su esfuerzo y constancia. Le Ferron parece trasladar a la Francia del XVI el clima de decadencia moral de la Roma retratada por Salustio. ¿Se trata de un reflejo de la realidad histórica de su tiempo? ¿O es, sin más, un tópico literario universalmente reconocido y reconocible? Verdaderamente, el lamento del humanista francés parece tener más de lo segundo que de lo primero; sobre todo si tenemos en cuenta el ambiente cultural que vivía por entonces Francia de la mano de un rey como Francisco I, quien para muchos fue un verdadero príncipe del Renacimiento, mecenas protector de las artes que lograría llevar hasta su corte a artistas como Andrea del Sarto o Leonardo da Vinci: ${ }^{29}$

Illustrandae autem patriae consilium, etsi optimum, seponendum semper ab hoc scribendi genere putabamus. Praemia autem nulla hoc tempore industriae constituta vidimus. Quippe illa honore liberalitateque alitur. Ea ubi dempseris,

${ }^{29}$ Leonardo pasó los tres últimos años de su vida en el castillo de Clos-Lucé, en Amboise, donde murió el 2 de mayo de 1519. 
parum sibi constant industriae fructus. Nunc vero cum divitiis magni laudabilesque homines fiant, ingenium, eloquentia, constantia, integritas refrixisse videntur, omnesque industriae fontes exaruisse, praesertim cum ad ingenii laudem parandam labore opus sit et sudore, ad opes parandas, qua cuique lubet nitatur. Ita fit ut homines docti, studiosi, industrii, ignoti sint, inter vulgus numerentur, nullo numero, nulla gratia, nulla authoritate habeantur: praemia eruditis debita districta teneantur a paucis (Le Ferron, De rebus gestis Gallorum, praef.).

Hasta cuatro veces aparece en este pasaje el término industria (o el adjetivo correspondiente, industrius), haciendo referencia a los malos tiempos que corren para quienes se esfuerzan: las recompensas debidas a la integridad, la erudición o la perseverancia, los tienen acaparados unos pocos privilegiados, concluye diciendo Le Ferron.

3. Por último, está la pretensión de veracidad. También para ello corren malos tiempos: resulta peligroso decir la verdad, nos dice Le Ferron. La virtud está atenazada, no existe el derecho ni la disciplina militar, etc. Con todo -termina diciendo-, el afán por decir la verdad y el servir de ejemplo a los hombres del futuro ha sido lo que le ha movido a escribir esta historia. El panorama que retrata el humanista francés nos recuerda significativamente el tono pesimista de un Salustio o un Tácito; y también algunas de sus expresiones: ${ }^{30}$

Veritatis autem studium, etsi nos movere maxime potuit, periculum tamen quod semper vidimus conflatum studiosis eius proponendae, odiorumque segetes inde gliscentes progredientesque, hoc praesertim tempore, quo virtutem alligatam videmus, forum sine fide, tribunalia sine iure, conculcatam disciplinam omnem militarem, omnium aetatum ordines simulatores dissimulatores, vel ipsos homines philosophiae sacris addictos ab hac provincia deterreret (Le Ferron, De rebus gestis Gallorum, praef.).

El final del proemio está transido de referencias y paráfrasis de autores clásicos, y en particular de Cicerón, ${ }^{31}$ algo habitual en este tipo de piezas programáticas renacentistas.

${ }^{30}$ La expresión simulatores dissimulatores constituye un claro eco del retrato de Catilina: cuius rei lubet simulator ac dissimulator (Sall. Cat. 5).

31 En particular se observan paráfrasis y citas exactas del De oratore, principalmente. También del Brutus, del Pro Sexto Roscio e incluso de la Rhetorica ad Herennium, atribuida desde la Antigüedad tardía a Cicerón y que circuló durante toda la Edad Media junto con otras obras retóricas ciceronianas. 


\section{TALIA DIXIT 15 (2020), 57-75}

\section{A modo de conclusión}

En medio de la corrupción moral de su convulso siglo, Salustio reivindica en los proemios de sus monografías la acción como medio de alcanzar fama y gloria. Había varias maneras de actuar. Él prefirió dedicar su retiro de la vida pública a una labor intelectual: escribir historia. Desde su consideración moralista de la historia, y de la mano de términos como industria, cura, labor o studium, Salustio convertirá su retiro de la vida política (ese merecido descanso, bonum otium, del que habla en el Bellum Catilinarium) en su último servicio a Roma, en un compromiso activo con su patria: el otium como negotium.

Industria es, en este sentido, un término vinculado a la escritura de la historia por parte del Salustio alejado de la política, ya en sus últimos años de vida. Como tal aparece varias veces en el proemio del Bellum Ingurthinum, y pervivirá con relativa asiduidad en los proemios historiográficos renacentistas; de manera especial en aquellos de tipo reflexivo que, como los de Salustio, dan cabida a consideraciones sobre el ser humano en general y sobre los bienes de la historia en particular. Más concretamente, el término industria aparece asociado a la legitimación de la labor del historiador, cuya importancia está como poco al mismo nivel que la del protagonista de los hechos, ya que es el motor que lleva al cronista a salvar del olvido los hechos del pasado, como refiere Bracciolini. En el caso de Arévalo, cuyo prefacio está jalonado con referencias a los proemios de Salustio, fue la industria de quienes escribieron los hechos del pasado la que dio fama a los griegos (y en su tiempo a los italianos), frente a los antiguos romanos, que como los castellanos de la época en que escribe Arévalo han preferido ejercitar su corpus antes que su ingenium. Por último, Le Ferron tiñe de un tono fingidamente pesimista el prefacio que nos ofrece de su historia de Francia, que está repleto de referencias clásicas, y de manera particular de Salustio, que de este modo se erigió en modelo de composición de muchos de los proemios historiográficos que se escribieron en los siglos XV y XVI por toda Europa.

Los tres ejemplos que hemos aducido bastan, a nuestro modo de ver, para asociar de forma clara el término industria a la utilidad e importancia que los historiadores reivindican para su labor en los proemios que sirven de presentación a sus escritos. Siempre con la figura de Salustio como referente último de esta reivindicación.

JOAQUín VILLALBA ÁlVAREZ villalba@unex.es

Universidad de Extremadura 


\section{BIBLIOGRAFÍA}

\section{Fuentes doctrinales}

Poggio Bracciolini (1993), Historiae de varietate fortunae (Edizione critica con introduzione e commento a cura di Outi Merisalo), Helsinki: Suomalainen Tiedeakatemia, .

Roderici Sanctii Episcopi Palentini Historiae Hispanicae Partes Quattuor, en Rerum hispanicarum scriptores aliquot, quorum nomina versa pagina indicabit, Ex Bibliotheca Roberti Beli Angli; Nunc accuratius emendatisque recusi, \& in duos tomos digesti, adiecto in fine Indice copiosissimo, Francofurti: Ex officina Andreae Wecheli, 1579.

Arnoldi Ferroni Burdigalensis, Regii Consiliarii, De rebus gestis Gallorum libri IX, Ad historiam Pauli Aemylij additi. Perducta historia usque ad tempora Henrici II Francorum Regis, Lutetiae, ex officina Typographica Michaëlis Vascosani, 1554.

Bibliografía básica.

Alvar Nuño, G. (2014), "Rodrigo Sánchez de Arévalo y la historiografía en el siglo XV", Ardua cernebant iuvenes. Actas del I Congreso Nacional Ganimedes de investigadores noveles de Filología Clásica (Estudios clásicos: Anejo 2), pp. 223-230.

Alvar Nuño, G. (2018), "La influencia de Alfonso de Cartagena en la Compendiosa Historia Hispanica de Rodrigo Sánchez de Arévalo", Revista de poética medieval 32: 19-48.

Benveniste, E. (1948), "Notes de vocabulaire latin”, Revue de Philologie, de Littérature et d'Histoire anciennes XXII, $\mathrm{n}^{\circ}$ 74: 117-126.

Bréal, M. (1897), Essai de Sémantique. Science des significations, Paris: Hachette.

Charlo Brea, L. (2002), "Medievalismo y Renacimiento en Sánchez de Arévalo: El prólogo de su obra Compendiosa Historia Hispanica" en Actas III Congreso Hispánico de Latín Medieval (León, 26-29 de Septiembre de 2001), León: Universidad de León, pp. 93-104.

Codoñer, C. (1986), La evolución del concepto de historiografía en Roma, Barcelona: UAB.

Earl, D. C. (1959), "Political terminology in Epistula ad Caesarem II", Museum Helveticum 16: 152-158.

Earl, D. C. (1961), The political Thought of Sallust, Cambridge: Cambridge University Press.

Fernández Gallardo, L., (2001-2002): "La Historia Hispanica de Rodrigo Sánchez de Arévalo: propaganda enriqueña y actitudes antihumanistas", Anthologica annua 48-49: 275-337.

Fontán, A. (2002), "La España de los humanistas", Humanismo y pervivencia del mundo clásico: homenaje al profesor Antonio Fontán (J. Ma Maestre Maestre, L. Charlo Brea, J. Pascual Barea, coords.), Vol. I, pp. 35-56. 
Fontán, A. (2008), Príncipes y Humanistas: Nebrija, Erasmo, Maquiavelo, More, Vives, Madrid: Marcial Pons.

Fryde E. B. (1983), Humanism and Renaissance Historiography, London: Hambledon Press.

Fubini, R. (2003a), Storiografia dell'umanesimo in Italia da Leonardo Bruni ad Annio da Viterbo, Roma: Edizioni di storia e letteratura.

Fubini, R. (2003b), "The theater of the world in the moral and historical thought of Poggio Bracciolini”", Humanism and Secularization. From Petrarch to Valla, Duke University Press.

Fubini, R. (2008), "Infelicità e melanconia del principe. Il pontificato di Niccolò V nella rappresentazione del Momus di Alberti", en Tirania: Aproximación a una figura del poder (Cappelli, G. M. \& Gómez Ramos, A., eds.), Madrid: Dykinson, pp. 161-186.

Fubini, R. \& S. Caroti (eds.), (1980), Poggio Bracciolini, 1380-1980. Nel VI centenario della nascita, Firenze: Biblioteca Medicea Laurenziana.

Fueter, E. (1953), Historia de la historiografía moderna, 2 vols., Buenos Aires: Nova (= Paris, 1914).

Giancotti, F. (1971), Strutture delle monografie di Sallustio e di Tacito, Messina-Firenze : G. D'Anna.

Kohut, K. (1980), “Sánchez de Arévalo (1404-1470) frente al Humanismo Italiano”, en E. Rugg \& A. M. Gordon (eds.), Actas del VI Congreso de la Asociación Internacional de Hispanistas, vol. 1, Toronto: University of Toronto, pp. 431-434.

Krantz, F. (2002), "Between Bruni and Macchiavelli: history, law and historicism in Poggio Bracciolini', en Ph. Mack \& M. C. Jacob (eds.), Politics and Culture in Early Modern Europe: Essays in Honour of H. G. Koenigsberger, Cambridge: Cambridge University Press (=1987).

La Penna, A. (1968), Sallustio e la 'rivoluzione' romana, Milano: Feltrinelli.

Maravall, J. A. (1953), "Sobre la naturaleza e historia en el Humanismo español", Historia de España. Estudios publicados en la revista Arbor, Madrid: CSIC, pp. 241261.

Maravall, J. A. (1954), El concepto de España en la Edad Media, Madrid: Instituto de Estudios Políticos.

Maravall, J. A. (1983), "El Pre-Renacimiento del siglo XV", en V. García de la Concha (ed.), Nebrija y la introducción del Renacimiento en España: III Academia literaria Renacentista, Salamanca: Universidad, pp. 17-36.

Miller, J. (2015), "Idealization and irony in Sallust's Jugurtha: the narrator's depiction of Rome before 146 B.C.", The Classical Quarterly 65.1: 242-252.

Rambaud, M. (1946), "Les prologues de Salluste et la démonstration morale dans son oeuvre", Révue des Études Latines 24: 115-130.

Smalley, B. (1971), "Sallust in the Middle Ages", en Classical influences on European Culture A.D. 500-1500 (edited by R. R. Bolgar), Cambridge: Cambridge University Press, pp. 165-176.

Tate, R. B. (1951), "Italian Humanism and Spanish Historiography of the fifteenth Century. A study of the Paralipomenon Hispaniae of Joan Margarit, Cardinal Bishop of Gerona", Bulletin of the John Rylands Library 34.1: 137-165.

Tate, R. B. (1970), Ensayos sobre la historiografía peninsular del siglo XV, Madrid: Gredos. 


\section{TALIA DIXIT 15 (2020), 57-75}

Tiffou, E. (1973), Essai sur la pensée morale de Salluste à la lumière de ses prologues, Paris: Klincksieck.

Valpy, F. E. J. (1828), An Etymological Dictionary of the Latin Language, London: Baldwin.

Villa Prieto, J. (2010), "La ideología goticista en los prehumanistas castellanos: Alonso de Cartagena y Rodrigo Sánchez de Arévalo. Sus consideraciones sobre la unidad hispano-visigoda y el reino astur-leonés", Territorio, Sociedad y Poder 5: 123-145.

Villalba Álvarez, J. (2009), Los proemios en la historiografía latina renacentista, Madrid, Ediciones Clásicas.

Villalba Álvarez, J. (2013), "El exemplum en los proemios historiográficos renacentistas", en Exempla fidem faciunt ( $\mathrm{M}^{\mathrm{a}}$ Luisa Harto Trujillo y J. Villalba Álvarez, eds.), Madrid: Ediciones Clásicas, pp. 263-282.

Villalba Álvarez, J. (en prensa), "Evolución del concepto de historia a través de los proemios historiográficos castellanos del siglo XV. La Crónica de Enrique IV de Diego Enríquez del Castillo", VI Congreso Internacional de Humanismo y Pervivencia del Mundo Clásico. Homenaje al profesor Eustaquio Sánchez Salor, Alcañiz-Madrid: CSIC. 